SMALL INTESTINE

\title{
Net digestive absorption and adaptive hyperphagia in adult short bowel patients
}

\author{
P Crenn, M C Morin, F Joly, S Penven, F Thuillier, B Messing
}

Gut 2004;53:1279-1286. doi: 10.1136/gut.2003.030601

See end of article for authors' affiliations

.....................

Correspondence to: Dr P Crenn,

Hepatogastroenterology

and Nutrition support

Department, Hôpital

Lariboisière, 2 rue

Ambroise Paré 75475

Paris Cedex 10, France;

pascal.crenn@

rrb.ap-hop-paris.fr

Revised version received 26 January 2004

Accepted for publication

16 March 2004

\begin{abstract}
Background and aims: Intestinal adaptation after small bowel resection in humans is debated. We have quantified in adult short bowel (remnant small bowel length $<2 \mathrm{~m}$ ) patients oral intake and net digestive absorption and their evolution over time.

Patients and methods: Oral intake and faecal output were studied over three days in 90 patients (39 and 51 without or with parenteral nutrition, respectively) and in 14 patients in early ( $<6$ months) and late (>6 months) periods after digestive continuity. Nitrogen and fat output were measured using chemiluminescence and Van de Kamer techniques, respectively.

Results: In the whole group, $81 \%$ of patients had hyperphagia (spontaneous oral intake $>1.5 \times$ resting energy expenditure), independently and negatively related to fat absorption $(p<0.01)$ and body mass index $(p<0.001)$ but not braked by the presence of parenteral nutrition. Protein and fat absorption were related to small bowel length. We observed, in the late in comparison with the early period after digestive continuity: an increase in oral intake ( $1.6 \vee 2.3$ resting energy expenditure), decrease in stool weight/oral intake ratio, no reduction in per cent fat absorption, and protein absorption improvement associated with a significant increase in the amount of protein absorbed ( $40 \vee 64 \mathrm{~g} /$ day; $p<0.05$ ), both being correlated with remnant small bowel length $(p<0.01)$.

Conclusions: This study confirms an adaptive hyperphagia in adult short bowel patients. Over time, hyperphagia and amount of protein absorbed increased, the latter being related to remnant small bowel length, indicating a behavioural adaptation that allows expression of intestinal absorptive adaptation.
\end{abstract}

$\mathrm{T}$ he main clinical consequence of extensive small bowel resection is water, mineral, and macronutrient malabsorption (that is, short bowel (SB) syndrome) leading to water-mineral and protein-energy deficiencies. Parenteral nutrition $(\mathrm{PN})$ is then the compensatory treatment of the malabsorption linked to this post surgical intestinal failure. Following the postoperative period, an adaptative phenomenon may occur to decrease the negative consequences of SB syndrome. Functional intestinal adaptation per se (that is, clinical improvement of absorptive capacity over time) is, at least in adults, a disputed phenomenon, ${ }^{23}$ despite convincing data for certain substrates, ${ }^{4-6}$ depending on the time of study and the SB circuit type. Many report have focused on the major role of oral intake to allow significant intestinal adaptation in animal models ${ }^{7-9}$ or in humans ${ }^{10-12}$ after intestinal resection. In addition, it has been shown in animal models that enteral nutrition or experimental hyperphagia is essential for the neuroendocrine cascades that induce functional and morphological adaptive hyperplastic and hypertrophic changes within the gut. ${ }^{13}$

Hyperphagia with high spontaneous oral hyperalimentation has been demonstrated previously in human adults with post surgical malabsorption ${ }^{14-16}$ and in patients with a remnant colon in continuity; an increase in colonic fermentation associated with bacterial adaptation that partially salvages malabsorbed carbohydrates. ${ }^{17-19}$ Hyperphagia can be defined by oral intake $>1.5$ times resting energy expenditure (REE), according to Harris-Benedict equations: in SB patients, this corresponds to metabolisable energy (that is, absorbed and non-excreted in urine for energy-balance equilibrium without PN). ${ }^{14}$ In the literature, it is generally accepted that time for full adaptation after intestinal resection may take up to two years in adult patients with colon in continuity. ${ }^{11} 122021$ Indeed, a surrogate marker of adaptation can be deduced from the time necessary for weaning off PN after re-establishment of digestive continuity: although two years was necessary for $95 \%$ of patients to be finally weaned off PN, 75\% of patients were weaned off during the first three months but this process took between six and 46 months for $19 \%$ of patients. ${ }^{1}$ These data suggest that, in a noticeable proportion of cases, late adaptation may take place in humans.

In order to evaluate and quantify intestinal adaptation at the net absorptive level, we assessed oral intake and net digestive absorption of protein and fat in an ambulatory cohort of non-stressed adult SB patients, followed in an approved Home PN centre for adults. Our aims were: (a) to determine explicative variables of oral intake, stool weight, and net absorption in a cross sectional study and (b) to quantify the role of re-establishment of digestive continuity in net digestive absorption and to study expression of the absorptive adaptation in relation to oral intake before and after six months post resection in two subgroups of patients.

\section{PATIENTS AND METHODS \\ Patients}

Criteria for inclusion in the study were: (a) extensive small bowel resection, with a remnant small bowel length $<200 \mathrm{~cm}$, with or without colonic resection; (b) absence or presence of residual small bowel lesions and, if present, with non-active ( $\alpha_{1}$-antitrypsin faecal clearance $<15 \mathrm{ml} /$ day $)$ or no occlusive stenoses; (c) absence of severe malnutrition (that is, of grade $\mathrm{C}$ according to the subjective global assessment of nutritional status classification of Detsky and colleagues $^{22}$; and (d) consumption of a diet ad libitum superior or equal to the estimated REE according to the Harris-Benedict equations using actual body weight, ${ }^{23}$ in

Abbreviations: PN, parenteral nutrition; SB, short bowel; REE, resting energy expenditure 
order to have interpretable absorptive data. Criteria for exclusion were: (a) reconstructive surgery of the remnant bowel, such as surgically reversed small bowel loop ${ }^{24}$; (b) existence of upper gastrointestinal tract surgery (oesophagus, stomach, duodenum, and/or pancreas); (c) organ failure other than digestive; (d) evolutive neoplasia; (e) exocrine pancreatic insufficiency; (f) small bowel fistulae; and (g) growth hormone treatment. ${ }^{25}{ }^{26}$ The dietary programme was based on free solid food ingestion ${ }^{15}$ with an ambulatory lifestyle, except for tap water restriction and, especially for end enterostomy patients, the use of either oral rehydration solution or mineral Vichy-St-Yorre water (Société Commerciale des Eaux Minérales du Bassin de Vichy, StYorre, France) containing $70 \mathrm{mmol}$ of $\mathrm{Na}$ /litre. None of the patients received enteral nutrition or were given oral supplements, oral medium chain triglycerides, or oral/ intravenous glutamine. All patients received transit slowing agents and gastric antisecretory drugs but none had received pancreatic enzyme or octreotide treatment.

Among a cohort of 104 consecutive SB patients evaluated for this cross sectional study between 1993 and 1998, 90 fulfilled the inclusion criteria and were studied for oral intake and faecal excreta, four (4\%) being excluded for insufficient oral intake. The metabolic investigation was performed after a median of $25(2-240)$ months following the most recent bowel surgery, including re-establishment of bowel continuity in 78 patients. Patient weight and size were measured during the investigation. The length of the post duodenal remnant small bowel, taken along the antimesenteric side of the small intestine with an opisometer, ${ }^{27}$ was the mean of measurements performed independently by two of the authors (PC, BM) on $x$ ray films of a barium meal follow through. The length of colon in continuity, expressed in terms of per cent of the usual length according to the method of Cummings and colleagues, ${ }^{28}$ was estimated from peroperative data records. Patients had not received $(n=39)$ or received $(\mathrm{n}=51)$ home $\mathrm{PN}$ for $27(2-187)$ months. Clinical characteristics of the patients are summarised in table 1 .
Among the 90 patients included, 12 were studied twice before and after a 1 (0.5-6) month delay following reestablishment of digestive continuity: in five and seven patients it was a jejuno-colic (type 2) and a jejuno-ileocolic (ileum length $45(1-130) \mathrm{cm}$ ) (type 3 ) anastomosis, respectively. Percentage of colon in continuity was $74 \%$ (14-100).

Fourteen other patients were studied twice after reestablishment of digestive continuity in early $(<6$ months: $2(1-4.5))$ and late (>6 months: $19(9-59))$ periods. No surgical change of digestive structures was performed during the interval. Ten and four patients had a jejuno-colic (type 2) and a jejuno-ileocolic (type 3 ) anastomosis, respectively, and five patients had residual small bowel lesions on $x$ ray film. In this subgroup, remnant jejunum and ileum lengths were 60 (5-150) and $0(0-26) \mathrm{cm}$, respectively, and percentage of colon in continuity was $74 \%(26-100)$. All of these 14 patients were receiving PN during the early period and seven (50\%) were weaned off PN at the moment of investigation in the late period.

\section{Oral intake evaluation}

Over a six day period, comprising a three day equilibrium period followed by a three day metabolic period, patients were requested to adhere to their usual spontaneous intake of energy, carbohydrates, fat, protein, and fibre. On a questionnaire, patients noted the nature and amount of foods at each meal, including snacks and nibbling, during the second three days, under the control of trained dieticians (MCM and $\mathrm{SP}$ ). Evaluation of intake was done by estimation of amount or by weight. Oral intake was unrestricted and comprised normal foods provided in a continental style meal. The major protein containing foods included beef, fish, eggs, chicken, cheese, and milk. Major fat sources included oil and butter. In this manner, each day's intake of total energy, protein, carbohydrates (total, complex, and simple), fat, fibre, and alcohol was calculated using Bilnut software. ${ }^{29}$ Calorie conversion factors used were those of Atwater et al confirmed by Southgate and Durnin ${ }^{30}: 4.2,9.35$, and $5.65 \mathrm{kcal} / \mathrm{g}$ for

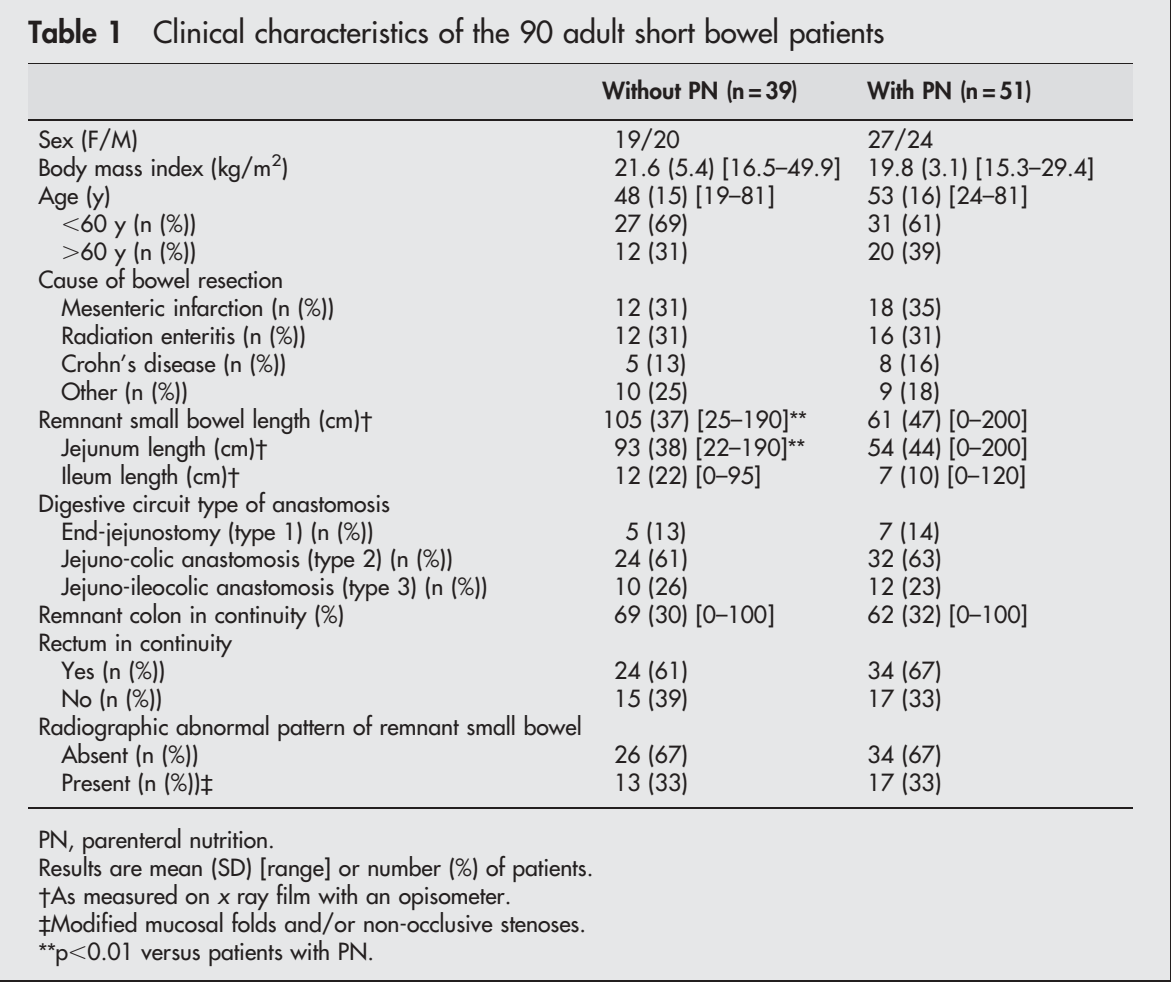


Table 2 Metabolic results of the 90 short bowel patients

\begin{tabular}{lcc}
\hline & Without PN (n=39) & With PN (n=51) \\
\hline Oral intake & $2667(817)[1425-4854]$ & $2507(844)[1345-4642]$ \\
$\mathrm{kcal} /$ day & $45.6(13.5)[25.4-74.6]$ & $48.1(16.3)[23-85.1]$ \\
$\mathrm{kcal} / \mathrm{kg} /$ day & $2.0(0.6)[1.1-3.2]$ & $2.0(0.6)[1.1-3.6]$ \\
Intake (\% REE) & $293(84)[158-478]$ & $272(99)[101-537]$ \\
Carbohydrates (g/day) & $120(38)[67-164]$ & $135(70)[39-297]$ \\
Total & $173(64)[89-319]$ & $137(64)[43-287]$ \\
Simple & $47(7)[30-71]$ & $45(6)[31-59]$ \\
Complex & $17(8)[6-42]$ & $15(8)[5-47]$ \\
Carbohydrates (\% of energy intake) & $97(34)[57-183]$ & $87(29)[48-187]$ \\
Fibre (g/day) & $20(2)[14-25]$ & $20(4)[14-29]$ \\
Protein (g/day) & $95(38)[34-205]$ & $94(37)[51-242]$ \\
Protein (\% of energy intake) & $33(6)[14-45]$ & $35(5)[24-49]$ \\
Fat (g/day) & $1312(1192)[166-5142]$ & $2526(1746)[240-7906]^{*}$ \\
Fat (\% of energy intake) & $61(24)[17-97]$ & $47(23)[0-89]^{*}$ \\
Stool weight (g/day) & $70(17)[37-94]$ & $52(21)[0-89]^{*}$ \\
Net digestive absorption (\%) & $73(19)[40-93] \dagger$ & $65(21)[18-100] \ddagger$ \\
Fat & $68(15)[51-91] \dagger$ & $57(18)[15-90] \ddagger$ \\
Protein & & \\
Carbohydrates & & \\
Calories & & \\
\hline Results are mean (SD) [range]. & & \\
REE, basal energy expenditure. & & \\
* $\mathrm{p}<0.05$ versus patients without PN. & & \\
tn=10; †n=29. & & \\
\hline
\end{tabular}

carbohydrates, fat, and protein, respectively. Values for intake were the mean of the three days of the metabolic period. For patients having undergone several absorption studies, the spontaneous amount of oral intake could be different.

\section{Stool analysis}

Digestive transit time was estimated using the transit time of a marker (red carmine) given orally with the first meal of the study period. The following 2-3 days, depending on the appearance of red carmine in stools, served as an equilibrium period, after which the metabolic period was begun. During the three day metabolic period, stools were collected daily. Faecal output analyses were performed on aliquots of three day pooled samples: briefly, little quantities of the three day stool collection were sampled after stool treatment by a special material (called Waren-Bolster) that mixes stool in order to obtain a homogenised biochemical composition. Nitrogen and fat were measured by chemiluminescence ${ }^{31}$ and Van de $\mathrm{Kamer}^{32}$ techniques, respectively. Bomb calorimetry measurement of total caloric content of stool $^{33}$ was performed for some patients. Calorie conversion factors used were those of Atwater and colleagues. ${ }^{30}$

\section{Absorption calculations}

Net absorption of protein and fat was calculated by subtracting the amount excreted in faeces (Out) from the amount ingested (In). The coefficient of net digestive absorption, expressed as a per cent of protein and fat, represented the proportion of ingested calories not recovered in faecal output:

Net digestive absorption $(\%)=(\mathrm{In}-\mathrm{Out}) / \mathrm{In}$

For patients having stool bomb calorimetry analysis, the number of carbohydrate calories was calculated from the difference between total calories and fat plus protein calories. The coefficient of net carbohydrate digestive absorption was calculated as above. Net total caloric absorption was calculated by subtracting calories excreted in faeces from calories ingested.

\section{Statistics}

Results are expressed as mean (SD) and/or median (range). Tests used for statistical significance were the Student's $t$ test, simple and multiple linear regressions for the whole group of patients, and the Wilcoxon test for the two subgroups of patients. For statistical analysis in those subgroups, we compared per cent and net intestinal absorption before and

Table 3 Explicative variables of stool weight, protein absorption, and fat absorption according to multivariate analysis in 90 adult short bowel patients

\begin{tabular}{|c|c|c|c|}
\hline & Stool weight & Fat absorption & Protein absorption \\
\hline Jejunum length & $\mathrm{p}<0.001$ & $\mathrm{p}<0.01$ & $p=0.001$ \\
\hline lleum length & $p<0.05$ & $p<0.05$ & $p<0.01$ \\
\hline $\begin{array}{l}\text { Radiographic abnormal pattern of remnant } \\
\text { small bowel }\end{array}$ & NS & NS & NS \\
\hline Presence of ileocaecal valve & NS & NS* & NS \\
\hline Per cent of colon in continuity & $\mathrm{p}<0.001$ & NS & NS \\
\hline Simple carbohydrate intake & $\mathrm{p}<0.001$ & & \\
\hline Protein intake & NS & & NS \\
\hline Fat intake & NS & $\mathrm{p}<0.05$ & \\
\hline \multicolumn{4}{|c|}{$\begin{array}{l}\text { * } \mathrm{p}=0.08 \text {. } \\
\text { The predictive equations for the three variables are: } \\
\text { stool weight }(\mathrm{g} / \text { day })=2989+9.63 \times \text { simple carbohydrate intake }(\mathrm{g} / \text { day })-12.51 \times \text { jejunum length }(\mathrm{cm})- \\
14.31 \times \text { ileum length }(\mathrm{cm})-18.75 \times \text { colon }(\% \text { in continuity); } \\
\text { net fat digestive absorption }(\%)=52.2+0.139 \times \text { jejunum length }(\mathrm{cm})+0.248 \times \text { ileum length }(\mathrm{cm})+11.35 \times \\
\text { ileocaecal valve }(\text { yes or no) }-0.142 \times \text { fat intake }(\mathrm{g} / \text { day); } \\
\text { net protein digestive absorption }(\%)=46.5+0.153 \times \text { jejunum length }(\mathrm{cm})+0.286 \times \text { ileum length }(\mathrm{cm}) .\end{array}$} \\
\hline
\end{tabular}




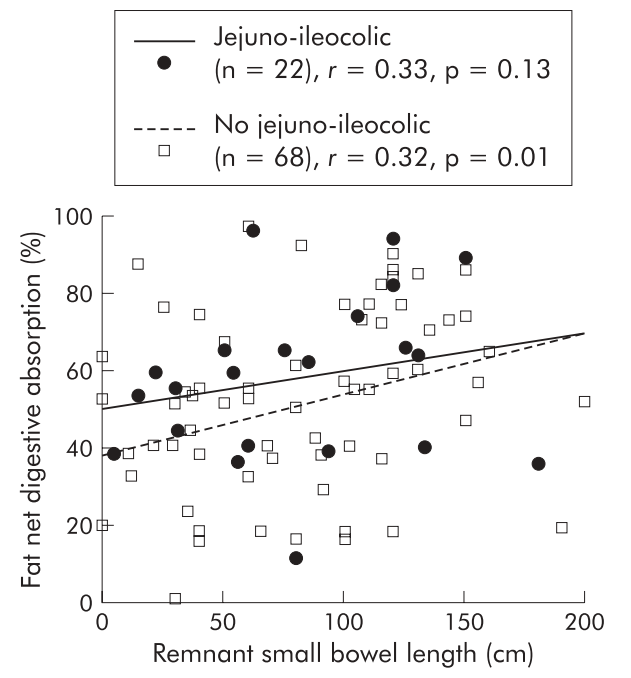

Figure 1 Correlation between net fat digestive absorption and remnant small bowel length according to the digestive circuit type of anastomosis (jejuno-ileocolic versus other types - that is, without remnant ileum and ileocaecal valve; $p<0.05$ ). Fat absorption was significantly correlated with remnant small bowel length (see table 3 ).

after re-establishment of digestive continuity $(\mathrm{n}=12)$ and, to assess spontaneous absorptive adaptation over time, early ( $<6$ months) and late (>6 months) investigations after digestive continuity $(n=14)$. A p value of $<0.05$ was used as the level of significance.

\section{RESULTS}

Explicative variables of oral intake, stool weight, and net absorption in the whole group $(n=90)$

Metabolic results for the 90 patients are shown table 2. Oral intake represented $2.0(0.6)$ (range 1.1-3.6) times the estimated REE. Eighty one per cent of patients had hyperphagia (that is, oral intake of more than $1.5 \times \mathrm{REE}$, including $41 \%$ with $1.5-2 \times$ REE, $33 \%$ with $2-3 \times$ REE, and $7 \%$ with oral intake greater than $3 \times \mathrm{REE}$ ).

Oral energy intake, expressed as kg of actual weight or per cent of estimated energy expenditure, was not significantly different in males and females, irrespective of weaning off PN (table 2), presence or absence of colon or radiographic abnormal patterns of remnant small bowel on $x$ ray film, age more or less than $60 \mathrm{y}$, or remnant small bowel length. A positive correlation between oral intake and delay separating resection and investigation was near the limit of significance $(p=0.07)$. In univariate and multivariate analysis, oral intake was negatively related to body mass index $(\mathrm{p}<0.001)$ and to net fat digestive absorption $(\mathrm{p}<0.01)$ but unrelated to net protein digestive absorption.

In univariate analysis, stool weight was negatively related to the presence of a rectum $(p=0.001)$, percentage of colon in continuity $(p<0.0001)$, and remnant jejunum $(p=0.02)$ and ileum $(\mathrm{p}<0.05)$ lengths, and positively correlated with total energy intake $(\mathrm{p}=0.04)$ and simple carbohydrate intake $(p<0.001)$. Stool weight was not significantly related to the presence or absence of an ileocaecal valve $(p=0.09)$, residual small bowel lesions on $x$ ray film, delay between time of bowel resection and time of investigation, or fat and protein intakes. In multivariate analysis, stool weight was still related to four variables (table 3 ).

In univariate analysis, net fat digestive absorption was positively related to the presence of an ileocaecal valve $(\mathrm{p}=$ $0.03)$ and remnant jejunum $(p=0.003)$ and ileum $(p=0.01)$ lengths, and negatively related to oral fat intake $(p=0.02)$. Between patients with jejuno-ileocolic anastomosis and other

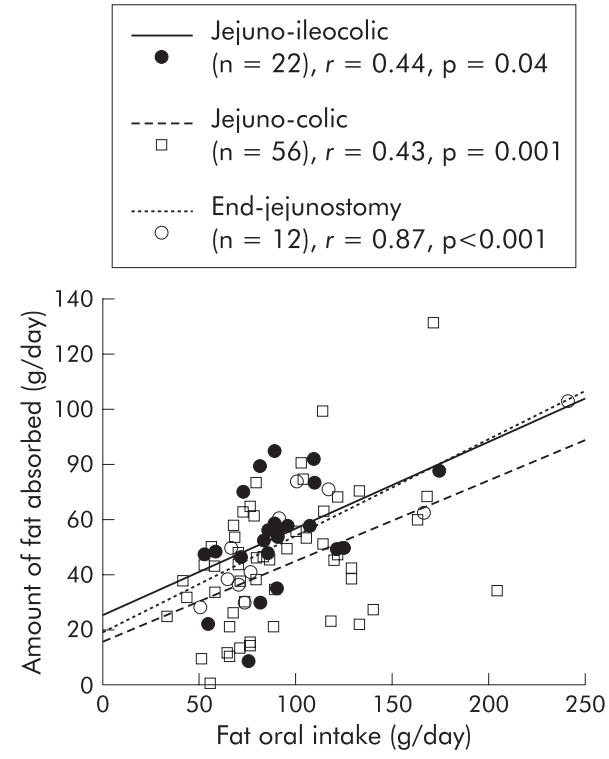

Figure 2 Correlation between fat absorbed and fat intake according to the digestive circuit type of anastomosis.

patients, the relation between net fat digestive absorption and remnant small bowel length was significantly different both for the slope $(0.10 \vee 0.162$, respectively $)$ and intercept ( $50 v 38$, respectively) (fig 1 ). Net fat digestive absorption was not related to percentage of colon in continuity, delay between resection and investigation, presence or absence of a rectum, or residual small bowel lesions on $x$ ray film. In multivariate analysis, net fat digestive absorption remained related to three variables (table 3 ). Regardless of the digestive circuit type of anastomosis, the amount of fat absorbed was dependent on fat intake $(\mathrm{p}<0.001)$ without an upper threshold (fig 2).

In univariate analysis, net protein digestive absorption was positively related to remnant jejunum $(p=0.006)$ and ileum $(\mathrm{p}=0.02)$ lengths and was not related to delay between
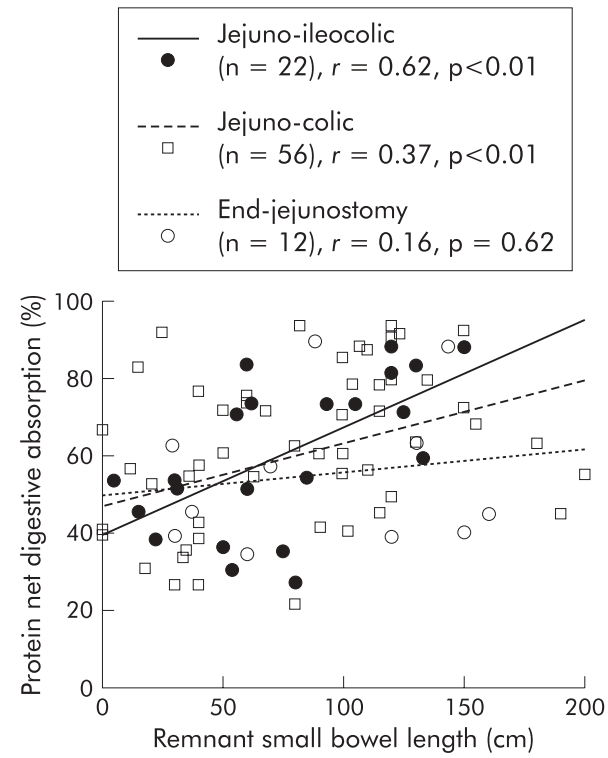

Figure 3 Correlation between net protein digestive absorption and remnant bowel length in the three digestive circuit type of anastomosis. Protein absorption was significantly correlated with remnant small bowel length (see table 3). 


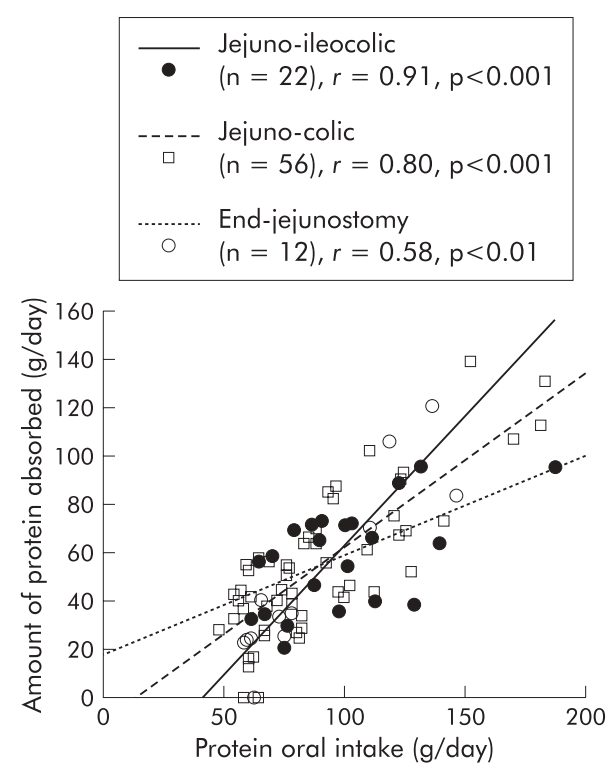

Figure 4 Correlation between protein absorbed and protein intake in relation to the digestive circuit type of anastomosis. There was no significant difference between the three digestive circuit types.

resection and investigation, oral protein intake, percentage of colon in continuity, or presence or absence of ileocaecal valve, rectum, or residual small bowel lesions on $x$ ray film. The slope and intercept of the relation between net protein digestive absorption and remnant small bowel length was not significantly different between the three digestive circuit types of anastomosis (fig 3). In multivariate analysis, net protein digestive absorption remained related to remnant small bowel length (table 3). Regardless of the digestive circuit type of anastomosis, the amount of protein absorbed was dependent on protein intake $(\mathrm{p}<0.001)$ without an upper threshold (fig 4).

Effect of digestive continuity re-establishment ( $n=12$ ) In the few months (that is, 1 (0.5-6) months) after reestablishment of digestive continuity, there was no significant change in energy, protein, carbohydrate, or fat intake. There was a decrease in stool weight (4000 (2700) g $v 1215$ (1300) g; $<<0.001$ ) and an increase in net protein absorption (32 (28)\% v $69(20) \% ; \mathrm{p}<0.01)$ and net fat absorption (38 (18)\% $v 68(21) \% ; p<0.01$ ) (fig 5), irrespective of the type of continuity (jejuno-ileocolic or jejuno-colic). In tested patients $(n=4)$, net carbohydrate and total calorie absorption increased $(36(6) \% \vee 75(20) \%, \mathrm{p}<0.05$; and $21(28) \% \vee 72$ (17)\%, respectively, $\mathrm{p}<0.05)$.

Spontaneous absorptive adaptation over time $(n=14)$ In comparison with the early period, in the late period we observed a significant increase in oral energy intake (40 (12) $v 54(19) \mathrm{kcal} / \mathrm{kg} / \mathrm{day}$ or $1.6(0.5) \quad v 2.3(0.7)$ times the estimated REE; $\mathrm{p}<0.05$ ) (fig 6), including protein (76 (29) $v$ 109 (34) g/day; p<0.03), carbohydrate (211 (57) v 320 (100) g/day; p=0.01), and fat (89 (29) v 112 (36) g/day; $\mathrm{p}=0.01)$ intakes. Seven $(50 \%)$ patients had hyperphagia in the early period and $14(100 \%)$ in the late period $(\mathrm{p}<0.01)$. Body weight and body mass index increased non-significantly. Stool weight decreased non-significantly between the early and late periods (2038 (924) v 1812 (1440) g/day, respectively) but the ratio stool weight (g/day)/oral intake (kcal/day) decreased significantly: $1.0 \quad(0.5) v 0.6 \quad(0.6)$, respectively; $\mathrm{p}<0.05)$. Independently of the presence or absence of ileum and an ileocaecal valve, there was no

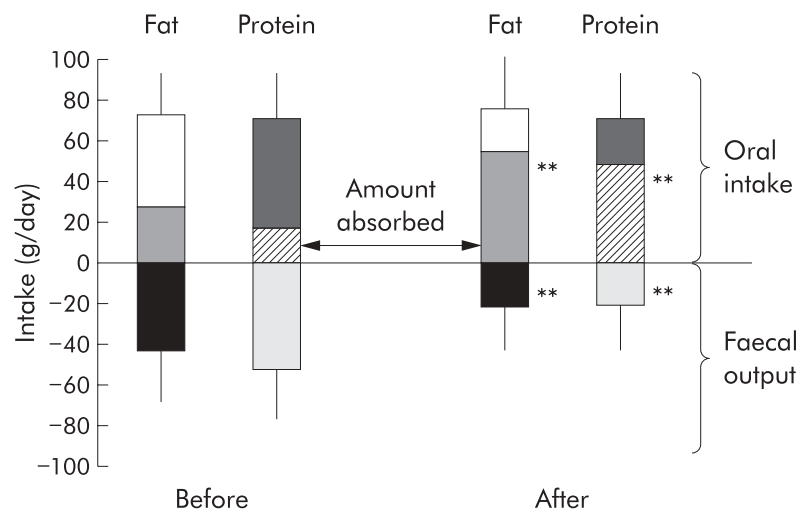

Figure 5 Fat and protein intake, faecal output, and net absorption before and after re-establishment of digestive continuity $(n=12$; five jejuno-colic and seven jejuno-ileocolic anastomosis). Values are means $(S D) ;{ }^{* *} p<0.01$, after versus before re-establishment of digestive continuity.

significant change in net fat digestive absorption (51 (24)\% v $47(20) \%)$ or amount of fat absorbed (46 (27) v $51(22) \mathrm{g} /$ day). Steatorrhoea increased non-significantly (43 (24) $v 60$ (31) g/day). In tested patients $(\mathrm{n}=3)$, net carbohydrate and total calorie absorption did not significantly change (60 (17)\% $v 64(18) \%$ and $63(5) \% \vee 60(5) \%$, respectively). In contrast, a trend $(\mathrm{p}=0.14)$ to improvement in net protein absorption was observed in the late period (48 (26)\% v 64 (15)\%) (fig 6), eight patients (57\%) showing an improvement in protein absorption by 37 (30)\% whereas no improvement was noted for six $(43 \%)$ patients. Faecal nitrogen did not change significantly (6.3 (3.4) v 6.9 (3.8) g/day); nevertheless, with the increase in protein intake, the amount of protein absorbed per se increased (40 (29) $v 68$ (21) g/day (fig 7) or $0.75(0.5) \quad v \quad 1.3 \quad(0.4) \mathrm{g} / \mathrm{kg} /$ day; $\mathrm{p}=0.04)$. In addition, serum albumin concentration, correlated to the amount of protein absorbed $(p=0.01)$, increased (32 (5) $v$
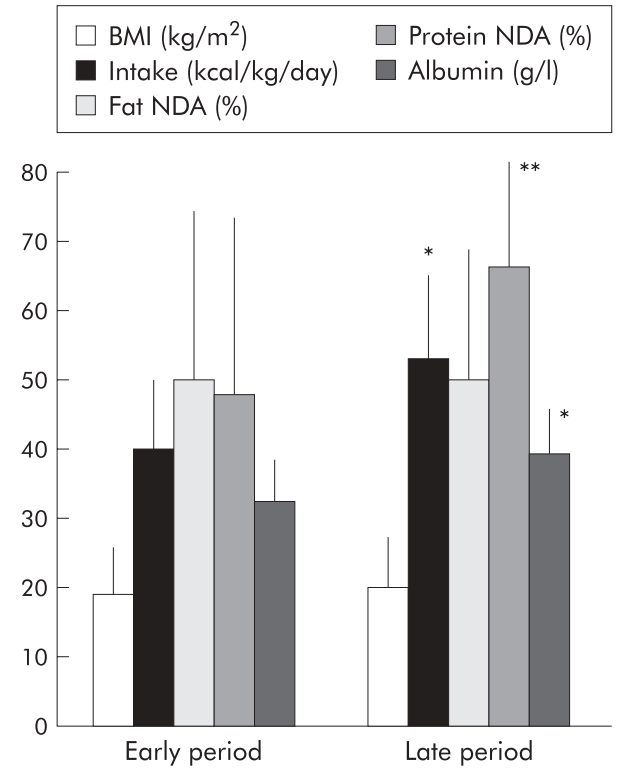

Figure 6 Body mass index (BMI), oral intake, net fat and protein digestive absorption (NDA), and serum albumin levels in short bowel patients $(n=14)$ at early (<6 months) and late ( $>6$ months - that is, 19 (9-59) months) periods following re-establishment of digestive continuity. Values are means (SD); ${ }^{*} p<0.05,{ }^{* *} p<0.01$, late versus early period. 


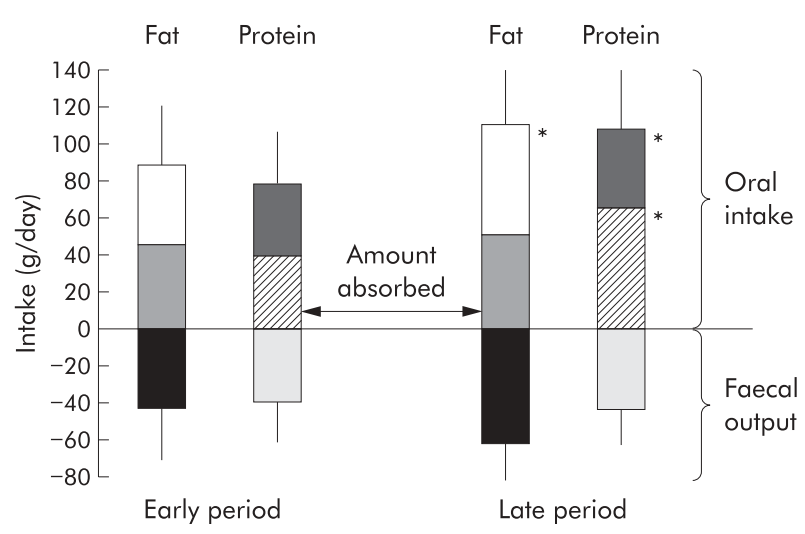

Figure 7 Fat and protein intake, faecal output, and absorption in early ( $<6$ months) and late (>6 months - that is, 19 (9-59) months) periods following re-establishment of digestive continuity $(n=14)$. Values are means (SD); ${ }^{*}<<0.05$, late versus early period following reestablishment of digestive continuity.

39 (5) g/l; p<0.01). Patients weaned off PN at the late period had a higher amount of protein absorbed than non-weaned patients $(1.6(0.3) v 0.9(0.2) \mathrm{g} / \mathrm{kg} /$ day, respectively; $\mathrm{p}<0.01)$. The difference in net protein absorption and amount of protein absorbed between the two periods was correlated to remnant small bowel length $(r=0.68$ and 0.73 , respectively; $\mathrm{p}<0.01$ ) (fig 8 ) but not to the difference in oral energy or protein intake.

\section{DISCUSSION}

Our population appears to be representative of SB patients with the three most frequent digestive circuit types of anastomosis. ${ }^{120}$ Small bowel length was accurately measured on $x$ ray film by opisometer, ${ }^{27}$ an element lacking in most studies. ${ }^{2}{ }^{17} 19$ Metabolic studies were done over three day periods, ${ }^{17}$ rather than one ${ }^{19}$ or two ${ }^{214}{ }^{1634}$ days, as this is the best compromise for useful digestive balance studies (in order to avoid significant intrasubject variations in faecal output) compared with seven or 10 day references. ${ }^{35}$ We estimated oral intake by dietary questionnaires because, despite a trend to overestimate fat intake and underestimate protein intake, we have previously shown that this type of recording was correlated with bomb calorimetry intake measurements. ${ }^{15}$ Only patients with sufficient oral intake (that is, greater than or equal to REE) were selected in order to avoid underestimation of net digestive absorption. ${ }^{15}$ Overall, in SB adult patients, we confirmed hyperphagia associated with free spontaneous oral alimentation for the majority. In a subgroup of patients, we showed that reestablishment of digestive continuity improved fat and protein absorption in less than six months by $30 \%$ and $37 \%$, respectively. In addition, after the early (six months) period following re-establishment of digestive continuity, we found a $15 \%$ improvement in protein, but not in fat, absorption, a fact that suggests a more than trivial spontaneous absorptive adaptation for protein.

Factors involved in stool weight and protein and fat absorption were in accordance with previous data that focused on the colon as a major determinant of stool weight, and on the small bowel for absorption of macronutrients, with the exception of carbohydrates, ${ }^{17} 1934$ a fact not examined in the present study. In our study, residual small bowel lesions on $x$ ray film were not a significant explicative factor for net absorption, probably because residual small bowel lesions were localised, non-active, and non-stenotic. ${ }^{19}$ For fat absorption, we did not find a threshold above which

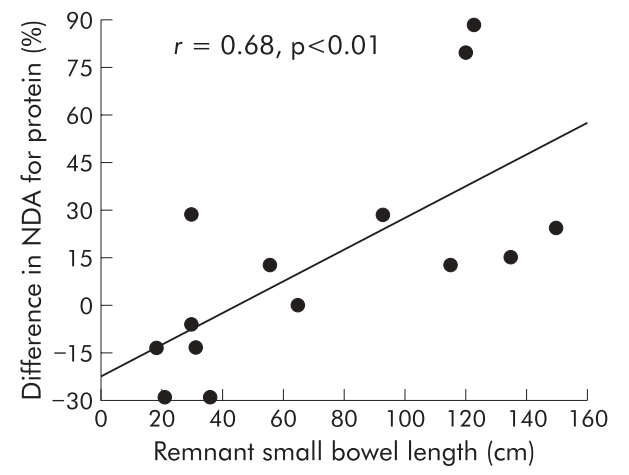

Figure 8 Relation between difference (late-early) in net protein digestive absorption (NDA) separating early ( $<6$ months) and late (>6 months - that is, 19 (9-59) months) periods following reestablishment of digestive continuity and remnant small bowel length $(n=14)$.

the amount absorbed was independent of the amount ingested, even in patients with a remnant ileum (that is, with a jejuno-ileocolic anastomosis) and partially preserved enterohepatic circulation of bile salts. ${ }^{36}$ This absence of threshold was previously observed in a patient with endjejunostomy where there was a close correlation between fat intake and faecal fat, ${ }^{37}$ and in 14 SB patients with or without a colon. ${ }^{17}$ This fact indicates a non-limited fat intake in SB patients. ${ }^{38}$

Clearly, re-establishment of digestive continuity has an important and early effect in decreasing stool weight but also in improving protein and fat absorption, confirming its major role in post resection adaptation. ${ }^{18} 2028$ Many mechanisms could be involved in the improvement in absorption of this surgery related absorptive adaptation. Firstly, re-establishment of digestive continuity increases transit time by creating continence regions facilitating better absorption as a result of a longer contact time; moreover, continuity re-establishment recreates feedback mechanisms such as ileal ${ }^{39}$ and/or colic $^{40}$ brakes, due in particular to PYY which delays gastric emptying and intestinal transit. ${ }^{41}$ Secondly, digestive bacterial flora is increased by 2-3-fold in patients with SB and a colon in continuity. ${ }^{18}$ In these patients, hyperfermentation of malabsorbed carbohydrates produces a high quantity of short chain fatty acids that are efficiently removed and absorbed from faecal water ${ }^{18}$ and increase sodium absorption. In addition, short chain fatty acids are trophic not only on colic mucosa but also on small bowel mucosa ${ }^{42}$; this could have speculatively improved intestinal absorption.

Our findings confirm hyperphagia in SB adult patients (that is, high spontaneous free oral intake ${ }^{14-16}$ with a mean of twice the REE). Hypercaloric and hyperproteinic (23\% of intake) hyperphagia was previously found in $10 \mathrm{SB}$ patients. ${ }^{15}$ Here we showed that it is not a transient phenomenon as it persisted and increased further even after the six month postoperative period. The increase over time in oral intake supports a spontaneous late adaptation. Therefore, it is important to encourage hyperphagia and promote oral intake in patients receiving long term PN. In the present study, we again observed that hyperphagia did not seem to be braked in patients receiving PN. ${ }^{15}$ In another study, hyperphagia appeared to be a consequence of malabsorption: in patients without malabsorption after intestinal surgery, there was a $27 \%$ reduction in oral intake in comparison with post resection malabsorptive patients. ${ }^{14}$ Hence hyperphagia appears to be a behavioural adaptive phenomenon: indeed, in our study, oral intake was negatively related to net fat digestive absorption and to body mass index. This suggests a 
compensatory mechanism to malabsorption, with patients increasing their oral food intake to improve nutritional status with the objective of recuperating their previous weight.

Between early and late periods following re-establishment of colon continuity, we found delayed spontaneous absorptive adaptation for protein but not for fat and, despite an increase in oral intake, a trend towards a decrease in stool weight $^{2}$ with a significant $40 \%$ decrease in the ratio stool weight/oral intake. The improvement in net protein absorption observed could be a result of intestinal adaptation per se. The method of net protein absorption was based on measurements of total nitrogen in faecal output, exogenous of oral intake but also endogenous. Bacterial faecal mass accounts for $60 \%$ of faecal nitrogen, ${ }^{43}$ the a $33 \%$ increase in dietary carbohydrates certainly increases bacterial mass and hence bacterial nitrogen: overestimation of exogenous nitrogen losses could therefore be postulated in such patients. The quantitative role of the colon for protein metabolism and absorption in SB patients is probable through urea metabolism and/or upregulation of specific transporters ${ }^{44}$ but this aspect is less known than for carbohydrates. ${ }^{19}$ In this study, the net amount of protein absorbed increased and this fact could explain, at least in part, the increase in serum albumin. ${ }^{45}$ Correlation of net protein absorption difference between early and late periods with remnant small bowel length suggests that only patients with a sufficient remnant small bowel enterocyte mass can improve their protein absorption capacity. Thus in severe SB syndrome, absorption capacity is difficult to improve but in patients with a higher intestinal mass, assessed by a longer small bowel length, absorptive adaptation can occur, probably facilitated by hyperphagia.

In contrast, in our study, there was no significant improvement in fat absorption over time. In fact, residual absorption of fat is one of the explicative factors of hyperphagia magnitude. In addition, it has been shown previously in rats that dietary fat, especially long chain triglycerides and free fatty acids, promote functional and anatomical adaptation after resection more efficiently than protein and polysaccharides. ${ }^{46}$ We cannot exclude the fact that fat absorptive adaptation could be very late, as was demonstrated for cholesterol absorption where adaptation took eight years. ${ }^{6}$ Finally, our study, in addition to a previous study of PN dependence, ${ }^{1}$ suggests that, at variance with previous assertions, ${ }^{2}$ digestive adaptation may occur subsequent to the early six month period following resection in a substantial number of adult patients. In this study, $50 \%$ of SB patients studied over time were weaned off $\mathrm{PN}$, a value similar to previous reports ${ }^{1}$ : increasing hyperphagia presumably allows the development and expression of maximal residual absorptive capacity. ${ }^{47}$

In summary, in addition to colic recovery, improvement in residual absorption in SB patients is due to adaptive hyperphagia. Hyperphagia seems to be stimulated by the severity of fat malabsorption and nutritional status. In patients with a sufficient intestinal mass and colonic continuity, hyperphagia increases over time, leading to an increase in protein absorption capacity and amount of protein absorbed. From a practical dietary point of view, an oral nutritional strategy in SB syndrome must aim to promote non-restricted hyperalimentation, with the exception of simple carbohydrates as they can increase diarrhoea, in order to stimulate intestinal absorptive adaptation.

\section{Authors' affiliations \\ P Crenn, M C Morin, F Joly, S Penven, F Thuillier, B Messing,}

Hepatogastroenterology and Nutrition Support Department, Lariboisière Hospital (AP-HP), 2 rue Ambroise Paré 75475 Paris Cedex 10, France

\section{REFERENCES}

1 Messing B, Crenn P, Beau P, et al. Long-term survival and parenteral nutritiondependency of adult patients with short bowel syndrome. Gastroenterology 1999; 117:1043-50.

2 Cosnes J, Carbonnel F, Beaugerie L, et al. Functional adaptation after extensive small bowel resection in humans. Eur J Gastroenterol Hepatol 1994;6:197-202

3 Powel-Tuck J. Don't expect too much of intestinal adaptation in short bowel syndrome. Eur J Gastroenterol Hepatol 1994;6:193-5.

4 Dowling RH, Booth CC. Functional compensation after small-bowel resection in man. Demonstration by direct measurement. Lancet 1966;ii: 146-7.

5 Gouttebel MC, Saint Aubert B, Astre C, et al. Intestinal adaptation in patients with short bowel syndrome. Measurement by calcium absorption. Dig Dis Sci 1989:34:709-15.

6 Koivisto P, Miettenen TA. Adaptation of cholesterol and bile acid metabolism and vitamin B12 absorption in the long-term follow-up after partial ileal bypass. Gastroenterology 1986;90:984-90.

7 Levine GM, Deren JJ, Steiger E, et al. Role of oral intake in maintenance of gut mass and disacharidase activity. Gastroenterology 1974;67:975-82.

8 Feldman EJ, Dowling RH, MCNaughton J, et al. Effects of oral versus intravenous nutrition on intestinal adaptation after small bowel resection in the dog. Gastroenterology 1976;70:712-19.

9 Levine GM, Deren JJ, Yezdimiz E. Small bowel resection: oral intake is the stimulus for hyperplasia. Am J Dig Dis 1976;21:542-6.

10 Biasco G, Callegari C, Lami F, et al. Intestinal morphological changes during oral refeeding in a patient previously treated with total parenteral nutrition for small bowel resection. Am J Gastroenterol 1984;79:585-8.

11 Goodlad RA, Nightingale JMD, Playford RJ. Intestinal adaptation. In: Nightingale J, ed. Intestinal failure. London: Greenwich Medical Media, 2001:243-60.

12 Buchman AL, Scolapio J, Fryer J. AGA technical review on short bowel syndrome and intestinal transplantation. Gastroenterology 2003;124:1111-34.

13 Bloom SR. Gut hormones in adaptation. Gut 1987;28(suppl 1):31-5.

14 Cosnes J, Lamy P, Beaugerie L, et al. Adaptive hyperphagia in patients with post-surgical malabsorption. Gastroenterology 1990;99:1814-19.

15 Messing B, Pigot $F$, Rongier $M$, et al. Intestinal absorption of free oral hyperalimentation in the very short bowel syndrome. Gastroenterology $1991 ; 100: 1502-8$.

16 Jeppesen PB, Mortensen PB. Intestinal failure defined by measurements of intestinal energy and wet weight absorption. Gut 2000:46:701-6.

17 Nordgaard I, Hansen BS, Mortensen PB. Colon as a digestive organ in patients with short bowel. Lancet 1994;343:373-6.

18 Briet F, Flourie B, Achour L, et al. Bacterial adaptation in patients with short bowel and colon in continuity. Gastroenterology 1995; 109:1446-53.

19 Nordgaard I, Hansen BS, Mortensen PB. Importance of colonic support for energy absorption as small bowel failure proceeds. Am J Clin Nutr 1996;64:222-31.

20 Nightingale JMD, Lennard-Jones JE, Gertner DJ, et al. Colonic preservation reduces need for parenteral therapy, increases incidence of renal stones, but does not change high prevalence of gall stones in patients with a short bowel. Gut 1992;33:1493-7.

21 Kurkchubashe AG, Rowe MI, Smith SD. Adaptation in short bowel syndrome: reassessing old limits. J Pediatr Surg 1993;28:1069-71.

22 Detsky AS, Mac Laughlin JR, Baker JP, et al. What is subjective global assessment of nutritional status? J Parent Enteral Nutr 1987;1 1:8-13.

23 Harris JA, Benedict FG. Standard basal metabolism constants for physiologists and clinicians. In: A biometric study of basal metabolism in man. Philadelphia: JB Lippincott, 1919:223-50 (publication 279).

24 Panis $Y$, Messing B, Rivet $P$, et al. Segmental reversal of the small bowel as an alternative to intestinal transplantation in patients with short bowel syndrome. Ann Surg 1997;225:401-7.

25 Byrne TA, Persinger RL, Young LS, et al. A new treatment for patients with short-bowel syndrome. Growth hormone, glutamine and a modified diet. Ann Surg 1995;222:243-55

26 Seguy D, Vahedi K, Kapel N, et al. Low-dose growth hormone in adult home parenteral nutrition-dependant short bowel syndrome patients: a positive study. Gastroenterology 2003;124:293-302.

27 Nightingale JMD, Bartram Cl, Lennard-Jones JE. Length of residual small bowel after partial resection: correlation between radiographic and surgical measurements. Gastrointest Radiol 1991;16:305-6.

28 Cummings JH, James WPT, Wiggins HS. Role of the colon in ileal resection diarrhoea. Lancet 1973;1:344-7.

29 Bourgerette P, Rolshansen M. BILNUT 4.0. SCDA Nutrisoft, Le Hallier, 37390 Cerellers, France, 1995.

30 Southgate DAT, Durnin JVGA. Calorie conversion factors. An experimental reassessment of the factors used in the calculation of the energy value of human diet. Br J Nutr 1970;24:517-35.

31 Ward MWN, Owens CWI, Rennie MJ. Nitrogen estimation in biological samples by use of chemiluminescence. Clin Chem 1980;26:1336-9.

32 Van de Kamer JH, Huihink H, Weyers HA. Rapid method for determination of fat in faeces. J Biol Chem 1949;177:347-55.

33 Miller DS, Payne PR. A ballistic bomb calorimeter. Br J Nutr 1959;13:501-8.

34 Cosnes J, Gendre JP, Lacaine F, et al. Y. Rôles compensateurs de l'iléon et du côlon restants après résection étendue de l'intestin grêle. Gastroenterol Clin Biol 1982;6:159-65. 
35 Bernier JJ, Florent C, Desmazures C, et al. Diagnosis of protein-losing enteropathy by gastrointestinal clearance of alphal-antitrypsine. Lancet 1978;2:763-4.

36 Hofmann AF, Poley JR. Role of bile acid malabsorption in the pathogenesis of diarrhea and steatorrhea in patients with ileal resection. I. Response to cholestyramine or replacement of dietary long-chain triglycerides by medium-chain triglycerides. Gastroenterology 1972;62:918-34.

37 Simko V, Mc Carrol AM, Goodman S. High fat diet in short bowel syndrome, intestinal absorption and gastro enteropancreatic hormone responses. Dig Dis Sci 1980;25:333-9.

38 Woolf GM, Miller C, Kurian R, et al. Diet for patients with a short bowel: high fat or high carbohydrate. Gastroenterology 1983:84:823-8

39 Pironi L, Stanghellini V, Miglioli M, et al. Fat-induced ileal brake in humans: a dose-dependent phenomenon correlated to the plasma levels of peptide $Y Y$. Gastroenterology 1993;105:733-9.

40 Nightingale JMD, Kamm MA, Van der Sijp JRM, et al. Disturbed gastric emptying in the short bowel syndrome. Evidence for a "colonic brake". Gut 1993;34:1171-6.
41 Nightingale JMD, Kamm MA, Van der Sijp JRM, et al. Gastrointestinal hormones in short bowel syndrome. Peptide YY may be the colonic brake to gastric emptying. Gut 1996;39:267-72

42 Kripple SA, Fox AD, Berman JM, et al. Stimulation of intestinal mucosalgrowth with intracolonic infusion of short-chain fatty acids. J Parent Ent Nutr 1989;13:109-16.

43 Stephen AM, Cummings JH. The microbial contribution to human faecal mass. $J$ Med Microbiol 1980;13:43-56.

44 Ziegler TR, Fernandez-Estivariz C, Gu LH, et al. Distribution of the $\mathrm{H}+$ /peptide transporter PepTl in human intestine: up-regulated expression in the colonic mucosal of patients with short bowel syndrome. Am J Clin Nutr 2002;75:922-30.

45 Hylander E, Ladefoged K, Jarnum S. Nitrogen absorption following smallintestinal resection. Scand J Gastroenterol 1980;15:853-8.

46 Grey VL, Garofalo C, Greenberg GR, et al. The adaptation of the small intestine after resection in response to free fatty acids. Am J Clin Nutr 1984;40:1235-42.

47 Wilmore DW, Dudrick SJ, Daly JM, et al. The role of nutrition in the adaptation of the small intestine after massive resection. Surg Gynecol Obst $1971 ; 132: 673-80$

\section{EDITOR'S QUIZ: GI SNAPSHOT}

\section{Answer}

From question on page 1278

The scanogram shows a right tension pneumothorax with a large volume of intrathoracic

fluid. On insertion of a chest drain there was release of air under pressure and bloodstained fluid with coffee ground effluent.

A diagnosis of spontaneous oesophageal rupture was made, subsequently confirmed at post mortem.

Diagnosis of oesophageal rupture requires a high index of suspicion. Mackler's triad of symptoms (vomiting, lower thoracic pain, and subcutaneous emphysema) is the classic presentation.

Management principles are control of the oesophageal leak, eradication of sepsis, reexpansion of the lungs, prevention of gastric reflux, nutritional and pulmonary support, administration of appropriate antibiotics, and postoperative drainage of sepsis.

Spontaneous rupture of the oesophagus is a great diagnostic mimic and tension pneumothorax is an extremely rare presentation of this condition. This patient had symptoms that mimicked a pulmonary embolus. Saturation and arterial blood gas improvements masked the severity of his symptoms. Other mistaken diagnoses include myocardial infarction, pancreatitis, perforated peptic ulcer, dissecting aortic aneurysm, and pericarditis.

doi: $10.1136 /$ gut.2003.033241 